\title{
Normative Institutionalism, Institutional Basis of Organizing
}

\section{Eva Bolfiková}

University of P.J. Šafárik in Košice, Faculty of Arts, Department of Political Science, Slovak Republic e-mail:eva.bolfikova@upjs.sk

\section{Daniela Hrehová}

Technical University in Košice, Department of Social Sciences, Slovak Republic e-mail:Daniela.Hrehova@tuke.sk

\section{Jana Frenová}

Faculty of Management, The University of Prešov, Slovak republic e-mail: ecperson@interdum.sk

\begin{abstract}
This article presents Weinberger's normative institutionalism and action theory as a basis for solution of selected questions connected with character of relation of institutionalized behaviour and formal organizations. It points out at possibilities of collaborative mechanisms vitalising in social systems and submits different statements or doubts concerning the substance of rational models of formal organizations and methodological individualism.
\end{abstract}

Key words: institution, institutionalization, organization, action theory, information.

\section{Introduction}

A social behaviour, which shows certain manifestations of regularity, repeatability or stereotyping of operations and actions, is directed towards creation of such behavioural models which in widely understood context gains institution character. Any form of organizing is not possible without existence of stable, for most of participating processors comprehensible and acceptable "manuals" for satisfaction of various needs and reaching of established goals. It is basis for creation of communication mechanisms at mutual exchange of information in processes of continual production of links and relations in any social unit in the moment when common interest 
exists which gives to these links and relations sense and purpose. In other words to enable organizing it is necessary that basic supporting mechanisms are developed in relevant social environment that has its substance in institutionalized behaviour. Such behaviour is based on existence of functional codes which contain specific, for most of members comprehensible, meanings. Knowledge of these codes and ability to understand their meanings is inevitable presumption for creation of organisation processes in environment where certain basic rules (standards) are applicable.

According to this, the social institutions area and their substance is key the essence of understanding and study of social organizing. Its connection to norms scope and substance of social existence normative background in all its manifestations help to orientate in searching for solutions for studying of social life organizational base. This approach represents "normative and regulative perspectives operating through the enforcement of rules and norms" (Baptista, 2009) and contrasts the cognitivecultural pillar of Scot's (2001) framework, that is corresponding with Institutional-Based Trust Theory (Zucker, 1986). According to Zucker, "institutions emerge through culture and shared value system, because these system „preserve dominant reward and sanction schemas" (Baptista, 2009:403). According to the cognitive-cultural perspective, institutionalized behaviour is determined by the relative stability, legitimacy and power of "common understanding that are seldom explicitly articulated" (Zucker, 1983).

Coleman (1991:704) on question about substance of social rules introduces the answer: „Social rules have two dimensions. In one respect, they are descriptions and characterizations of what people do as a rule. As such, they correspond closely to Austin's „habits of obedience“ (1954). Habits of obedience, however, lack a normative dimension. By conceiving of these habits as motivated by the credible threats of the sovereign, Austin fails to address this second, normative dimension." Social rules can have normative force in that they have a prescriptive or reason-giving dimension. Whether they provide reasons for action depends on citizens accepting them from an internal point of view.

\section{Normative institutionalism by Weinberger}

The classical means of normative institutionalism (March and Olson, 1984) offer one of the possible framework for the institutional basis of organizational analysis. Especially because of: 1 . they emphasize the relevance of norms, and 2. they view the institutions as a tools, that form the basic framework for individual action in the social processes.

Based on O. Weinberger (1995) and his understanding of substance of normative institutionalism it can be distinguished between investigation of standard as: a) thought entity - in sphere of normative ideal essences (as thought, idea, abstraction which "is here even when it's not performed"), b) social reality - social existence of standards as sociological reality which is possible to establish only empirically on basis of experience in real action performed by real subject (social conditions - real 
for realization of idea realization). Problem of social standard existence as social fact meets with attitudes of positivistic conceptions - Schauer's presumptive positivism (1991), Raz (1984) but also law's sociology.

Normative institutionalism tries to answer the question " in which lies social existence of norms (to whom they are addressed, in what environment, what is their form) and what functions have norms in social reality" (Weinberger, 1995:15).

Concerning organizing it is necessary to solve continually the problem of goal reaching through processes of organizing, coordination and cooperation. Basis of these processes is existence of more or less functional rules which respecting is a presumption of effective behaviour in relation to reaching the established goals formulated on basis of common interest. Rules or norms and institutions are related to each other very closely when continuous consideration aims towards understanding of rule existence as basis for creation of models and behaviour patterns defined as social institutions. It is possible than to talk about normative determination of social institutions which contains: 1. necessity of rules as behaviour regulators which are understood by social environment - as presumption of establishing and function of institutions, but at the same time 2. immanently (in its substance) in institutions, where is contained character of regulator as pattern or behaviour model which enables to answer question "how?" (to satisfy needs and reach goals).

Tuomela (1995:138, see also Tuomela and Balzer, 1999) has elsewhere briefly sketched an account of social institutions that emphasizes the normative character of social institutions. "This account relies on two kinds of collectivity "made" and accepted social norms: 1. formal or informal rule-norms („r-norms“ - r-institutions), which are based, directly or indirectly, on group-authorized agreement-making and 2. proper social norms („s-norms“ - s-institutions), which are eigher society-wide or group-specific norms based on normative collective expectations and require action in response to them" (1995:139). Tuomela solves also problem of social institution genesis in context of collective activity meaning.

Weinberger investigates which relations exist between norms and institutions on basis of reasoning about action theory.

In most general meaning an action can be described as that part of human behaviour which is purpose-oriented, i.e. focused on reaching of more or less specific goals with using of available resources. Action is than basis, presumption and part of decision-making processes which in organizational environment gains specific character and forms. Inevitable presumption of any decision-making is availability of information therefore Weinberger approach and his action theory is very productive material for study of institutional background of formal organizations.

As part of each decision-making is information processing, it is acceptable that Weinberger understands acting as behaviour determined by information i.e. substance of action is explained by structure of information processing processes which determines action. Action is behaviour regulated by the will, i.e. behaviour which 
is determined mainly by goal and purpose determination, intentional behaviour. Among information processing processes which determine action belong necessarily processing of practical as well as descriptive information.

\section{1. Two types of information - descriptive and practical}

Information processing processes or information processing procedures work in relation to two types of information. These enable basic orientation in decisionmaking area and enable to proceed towards reaching of goals for sake of purposes which characterize meaning of all current operations. Character of this information follows stabilizing and dynamizing elements of decision-making and also indicate manner in which information can be processed and their purpose. Action is actually possible only if subject of action has available relevant information.

We distinguish two types of information: 1. about the state of matters, i.e. theoretical, descriptive information, 2. about how is possible to solve certain technical tasks (programs, projects, know-how, solution guidelines including interpretations of descriptive information and finding their contexts) - practical information.

Specific meaning in decision-making process or in process of information processing have except these two types of information, information which provide knowledge about progressing state in action process - feedback information. Practical information are opposite to theoretical, descriptive sentences:

1. Main meaning difference lies in fundamentally different pragmatic functions. Theoretical sentences are those which describe, while our effort is to reach adequate correspondence of descriptive sentences - or its content - with real state of matters in the world.

Practical sentences have pragmatic function to determine directly or indirectly how should the world be and how it is possible to create or change it through action.

2. Practical sentences are principally system-relative which enables that these sentences are valid in one system while they are not valid in other system.

3. Practical sentences are not true in same sense as theoretical sentences. They can't be explained by experiment and observation; they can't be tested by reality of the world. Their reasoning depends on other assumed (accepted) practical sentences. Also experience, specifically assessment experience can be integrated into practical reasoning. For example it is possible hypothetically in mind to prefer subject A over subject B - marriage over friendship - and to test this relative assessment (length of duration, value structures ...). Practical sentences can be tested only through other (mediatory) "sentences", not directly (through indicators, through testimonies of people (respondents) about phenomenon.

While descriptive sentences can be marked as true or untrue, practical information misses the truth value, they can be more valid and void. For example normative sentence can't be true or untrue but valid or void. 


\subsection{Normative sentences}

Action process is always performed in environment where activity of participants are concerning common interest's solution and reaching the common important goals regulated by functional normative system. For social action are as standard-making important two types of normative sentences as basement for creation of norms 1 . elementary normative sentences and 2. combined normative sentences.

Elementary normative sentences are created by normative operator and issue of fact description as its argument. It is useful to come from two basic normative operators: 1. operator "shall be" and 2. operator "may be" (to the philosophical question "shall be" and "may be" see more Geffert, 2008:52). As exclusively regulative function have only sentences "shall be" (because sentences "may be" don't exclude any alternative), these shall be substance of normative system (each system of norms). "May be" sentences have only secondary function: they express limitation or deletion of what "shall be". They indicate possibility to create variations, alternatives, modifications, reconstructions by which they contribute to support, maintenance and enlargement of action freedom space.

It is necessary to distinguish between open and closed system of norms, only in closed ones is applicable "What is not forbidden is permitted". Further it is necessary to distinguish strong and weak permissibility: 1.P is strongly permitted if it is explicitly permitted or even ordered, 2. $P$ is weakly permitted if there doesn't exist any forbiddance of $P$ within the system.

Based on Veblen understanding regarding understanding of character of constructing of current society, dominancy of operator "shall be" can be assigned to systems which he calls manipulative, while dominancy of "may be" operator is typical for so called cooperative systems (Harvey and Katovich, 1992).

Combined normative sentences - they are created using standard-making functors (they are not truth functors). They are defined using characteristic rules of resulting consequences. This way can be used also in definition of conditioning functor of norms. They are created as combination of elementary sentences (e.g. if "A" must be than "B" must be, if A must be, than B may be, if the condition " $\mathrm{A}$ " is met than must (may, mustn't') be "B", if " $\mathrm{A}$ " must be and "B" may be than "C" mustn't be etc.).

\subsection{Action theory}

Weinberger's theory of action, in version in which is submitted, based on Searl's conception of human action (1995) as being responsive to "external reasons" - in strong contribution of information and communication theory, institution theory and theory of norms - is very efficient tool for solution of formal organization institutional background problems. Despite doubts of some authors about Searl's theory of social reality (Viskovatoff, 2003), it is possible to consider as suitable starting point and basis for further analyses of social action and for study of social institutions, mainly on normativist level. 
Weinberger's understanding of action theory is formal-finalistic in double relation:

1. characterizes action as process of information processing which can be addressed to each subject (unit, group, community, society) - not only to psychophysical persons or individuals - as it is submitted by $\mathrm{M}$. Weber in his substance of understanding approach to social phenomenon study. „The new institutionalism in organization theory and sociology comprises a rejection of rational-actor models, an interest in institutions as independent variables, a turn toward cognitive and cultural explanations, and an interest in properties of supraindividual units of analysis that cannot be reduced to aggregations or direct consequences of individuals' attributes or motives“ (DiMaggio and Powel, 1991:8). „No social process can be understood save as it is located in the behaviour of individuals..." (Selznick, 1957:4).

2. it is based on finality theory as it is based on the term of causal relation given in advance (it means that phenomenon are perceived as deterministic as it is applicable that relation between cause and consequence is determined, that we know what is the cause and we know what we observe as a consequence causality direction is stated).

Concept of action can be relate not only to psycho-physical action actors. Human and buman society is constituted so, that there exists also other - institutional action actors. There exists collective action, action of organizations which perform their authorities, etc.

Most simple way how to characterize formal-finalistic theory of action is to compare it at least in several points with other action concepts: 1. What distinguish action from other forms of behaviour?, 2. Is action related to term freedom of action and how is it possible to explain freedom of action or its determinisms?, 3. How is it possible to explain content of individual's action? How is explained action motivation and performance of decision-making, 4. How is explained influence of individual - society relation on action?

Ad 1. Action differs significantly from other kinds of behaviour or other systems. For defining of the term action is crucial that action is determined and managed by information process using descriptive information, it is not instinctive behaviour or spontaneous (unintended), it aims towards decision-making (making of decisions). Consciousness is secondary not primary constitutive sign of action (conscious is understood as rational and logic) as some information are processed "intuitively", "with feeling". Consciousness is so possible but not inevitable for processing of information - and decision-making.

Ad 2. Action is understood as behaviour determined by special information process. This information process has to be expressed in scope of action alternatives. Action can exists only there are spaces for action i.e. where subject has possibility of choice between various continuations of behaviour trajectory (variants and alternatives of procedures and solutions). 
In accordance with bifurcation of behaviour trajectory to alternatives, variants between which is decided on basis of information process freedom is conceptual presumption of action. It is very important attribute of action, without freedom it is not possible to adequately consider the action.

M. Weber proceed conversely and he preferred intensive regulation, control, mechanisms of strong centralism, so to the space without freedom. Weber's action is related to individual in usually not free space, strongly regulated and limited concerning possibilities of solutions development as products of choice and decision-making. It means that space of freedom is strongly limited or not possible at all in rational systems (bureaucracy) where emphasize put on predictability and controllability leads to narrowing of possible decision-making to usually in advance stated procedures or behavioural patterns. This space is limited also by strong orientation on only one possible result - effective maximization of subject benefit (in individual person's action).

Ad 3. Presumption for action is always active approach of system (subject) to which is the action attributed. Each living being has included (immanently) certain kind of activity and this is applicable analogically also in social systems. This activity is manifested in habitualized behavioural patterns (i.e. those which are result of learning of habits, customs, norms, institutions, patterns in specific social conditions). Information process, information processing related to decision-making, influences content of action.

Content of action can be identified on basis of motives which are presumption and part of purpose and goal development formulated as expression of common interest and creation of direction. When we talk about motives, we think on what determines action or explain way (content) of subject action. A reason for action is internal if it is part of the agent's "subjective motivational set" (Williams, 1981:102). Searl in his construct of normativity emphasizes also the external reasons, by that agents can be influenced.

Motive - reason, explanation, of action, final reason of action. Final motives represent core of motivation. The game enters also other determinants, mainly autonomous or heteronomous fixed norms.

Explanation of action is possible using motive interpretation, i.e. reconstruction of information process determining action. Motives are than basically interpreted purposes. Usually plays this role not only one but more purposes.

Ad 4. Human acting depends on relation between individual and societies and also social institutions.

Habitualized behavioural patterns and purposes which the individual follows are signated not only with his internal, biologic needs but considerably also by following other people behavioural patterns. "Habit means special sensitiveness or accessibility to certain classes of stimuli, standing predilections and aversions, rather than bare 
recurrence of specific acts" (Dewey, 1930 In: Jensen, 1987:1044).

Action is often interaction between more subjects or collective acting, activities of individual are often composed into behavioural norms and they are determined by expectations in relation to action of "other people or societies" (Dobiaš, 2009:30).

\subsection{Institutionalization and institutions}

Defining or limitation of institutions is a task which put high demands on explanation of at least few problems. These are related mainly to area of norms but also social reality, social roles, social relations, ways of creation stereotypes and regularities in social behaviour of individual and group etc.

Regarding this Weinberger emphasizes: 1. absence of clear definition of the term "institution", 2. need to limit the institution sphere, 3. necessity to submit comprehensive classification or typology of institutions.

Weinberger works with Searl's theory of institutions which ask questions regarding "institutional facts" (Searle, 1995:2) and their origin in social reality. Searle argues, that "all of institutional reality can be explained" by means of three notions that he develops - collective intentionality, the assignment of function, and constitutive rules (Searle, 1998:124).

Social institutions are taken to be norm-governed social practices introducing a new social and conceptual status on the practices or some elements involved in those practices (Tuomela, 2003:123). Such formulated definition has its starting point in collective acceptance. Author presumes it with knowledge that the word "institution" is often used rather vaguely.

Weinberger tries to state relevant signs of the term, what shall serve as explanation why he uses the term "institution" as basic term of social-science and legal-science research.

An institution concept shall surround sphere of our study so the buman action could be understood and explained as summary of wanting, action and connection of individuals with social factors and also framework culture conditions. For investigation of such understood institution is necessary existence of coordination between individual and society (social agreement - as basic norm).

Phenomenon of institutionalization exists in each community. What behaves as pattern or model of behaviour, as way of acting or as interaction system has, in certain circumstances, tendency to institutionalize - to stabilize in its form and gain the character of social reality with relatively independent, own life, it becomes model which co-create form of life.

In the literature can be observed a wide range of temporal dynamics associated with process of institutionalization: "new practices, rules, and technologies emerge, 
diffuse, and become legitimated over time and at varying rates" (Lawrence, Winn and Jennings, 2001:8). Several typologies of institutional mechanisms have been proposed (e.g., DiMaggio and Powel, 1983, Powell, 1991; Scott, 1991, 1995).

Lawrence, Winn and Jennings (2001) argue, that the traditional model of institutionalization as typified by the S-shaped diffusion curve (Powell and DiMaggio, 1991; Rogers, 1995; Strang and Tuma, 1993) masks a variety of temporal patterns in institutionalization. They propose an alternative set of institutionalization curves based on the type of institutional mechanisms agents use to support the process, more exactly the heterogeneous set of "processes“ (Clarc, 1985) (dynamic aspects of institutionalization). The pace of institutionalization is defined by Lawrence, Winn and Jennings (2001) as the length of time taken for an innovation to become diffused throughout an organizational (or societal) field.

Institutionalization as process exceeds innovation aspect and includes production and development of behavioural models as well as its transformation and modification tendencies in its current environment. Despite it mechanisms which support institutionalization process can be accepted in Lawrence, Winn and Jennings (2001) conception.

According to Selznick the institutionalization is a neutral idea, which can be defined as "the emergency of orderly, stable, socially integrating patterns out of unstable, loosely organized, or narrowly technical activities" (Broom and Selznick, 1955:238). „Institutionalization constrains conduct in two main ways: by bringing it within a normative order, and by making it hostage to its own history“ (Selznick, 1992:232).

DiMagio and Powell (1983) explained three mechanisms for institucionalization: 1. coercive, 2. normative and 3. mimetic pressures. Coercive pressure is often associated with the state and refers to the threat or actual use of force by a powerful actor in order to gain compliance. Normative pressure stems from cultural expectations that actors feel compelled to honour. Mimetic pressure involves the perception of some value of mimicking behaviour from other referent actor (Lawrence, Winn and Jennings, 2001).

Lawrence, Winn and Jennings (2001) suggest for defining of institutionalization mechanism combination of 1 . influence and discipline, 2. force and domination with respect to the concept of power - episodic and systemic.

Definition of institution has to satisfy four requirements: 1. to connect on naturalized usage of language, sharpen and correct it, 2. to be usable creative mean for presented theory, 3. to be sufficiently universal (for usage in various areas of study and management and for various purposes), 4 . it has to be accessible to specification considering specific conditions of application.

Problem of limit sharpness of the institution term moves effort for its definition to approach that only what is socially entrenched and relatively stabilized can be regarded as institution. 
Institutions are systems of human behaviour. There is contained core of practical information. In this regard they are always complex phenomenon if they consist of arranged system of practical information which is related to effect of psychic and social facts and procedures (Weinberger, 1995).

Searle (1995) works with construct institutional facts in this view. He suggests the three basic ingredients in creation of institutional facts: „1. the imposition of a new function on an entity, 2. collective intentionality and 3. the distinction between constitutive and regulative rules“ (1995:28).

Tuomela (2003:141) suggests following classification of increasingly stronger social institutions can now be usefully proposed in view of or discussion: 1. institution as norm-governed social practice, 2 . institution confering a new conceptual and social status to some entity (e.g., person, object, or activity), 3. institution conferring a new deontic status and status functions to go with it to the members of the collective in question, 4. institution as an organization involving social positions and a task-right system.

Last definition position is for our access relevant at most, it presume identification of relation institution and organization in dynamic of normative systems, subject of organizing and position characteristics. Tuomela calls this position "standard" cases of social institutions (Tuomela 2003:141), that don't excludes the activation of another meaning in the framework of the classification. It also argues, that „all institutions are normative in some sense allthough not always in one and the same sense“ (2003:147).

Perri (2003:395) defines the institution as a „formal or informal constraining social rule, convention or norm, in according with approach of North (1990:3), which structures interaction, which is recognized by those subject to it (by Knight, 1992:2), as creating an accountability or some duty to provide an account of performance and be subject to appraisal and either sanction or reward, however informal (by Douglas, 1980, 1986), and which leads to the forming of more or less stable social patterns (by Jepperson, 1991:145)“ (for a review of definitions, see Peters, 1999).

Term institution signs special type of generic term: always where we talk about institution it is something having analogical core. It means that each institution presents model of behaviour which has its substance (core), which provides preservation of its substance also in number of empiric variants (for example marriage as institution can have various form in historical development or regarding various cultures but core of this institution enables stability of its substance) - this are relation between individuals and societies, relation with certain tendency to durability, relative regularity a normative regulation - individual institutions have however different nature so it is not possible to fix unique class of definition signs.

Important elements which lead to statement of the term institution (by Weinberger): 1. Human life and action are characterized by relation between action of 
individual subject (individuals, groups, organizations) and societies. Behaviour of individual depends on social relations: his individual action is signed with relations to surrounding, inherited abilities, internalized models, when important is also active creative influencing and modification of behavioural patterns from the individual's side. Human behavior is also fundamentally determined by the axiological system of the individual but also by the systems of values of particular social groups (Geffert, 2010a:87).

2. Term institution is related to term institutionalization, process of development of institutions. Institutions always means some kind of stabilization, development of models, standards, and life forms which are characterized by certain relative stability, not constancy or changelessness. They are orientations, directions of action and also elements of social reality and basis of all kinds of social action. Institutions are sphere where these fixings are created in certain chaining of individual and social.

3. Institutions contains systems of practical information, approaches, guidelines, standardized procedures - how to act. Without institutions action would be impossible. For example action towards gaining of resources for cultural sights protection project in municipality would have available only descriptive information, we would know what is cultural sights protection but we wouldn't know how to provide it, we would know what should contain the project (project structure) but we wouldn't know how to provide it. It is not easy to state relations between institutions as observable social realities and applicable systems of norms and values. Effective action, learning and all forms of social action presume certain fixing of intentions (motives, intents, and purposes) and setting of norms of behaviour. All institutionalized contains core of normative regulation. Institutions are not only certain regularities of individuals and societies but they are connected also with "shall be" rules. Each man as individual has practical attitudes and each social situation brings into life practical attitudes and norms. For example institute of marriage contains "shall be" - two and more partners (not only one), formalization of cohabitation (not free) even way of formalization can be different, accepted by social environment (including legal norms).

4. Emerging and social existence of institutions lies on buman interaction, on constitution of tasks and connections of value beliefs of acting people. We talk about basic consensus about value standards. It is not right to assume that correspondence of value attitudes of all participating people - basic consensus - is required to establish institution or even that institutions are established on grounds of this basic consensus. There is possibility that institution is possible only on basis of various attitudes. For example marriage as social fact has also its value dimension (extent) - in consensus as wide social approval created meaning, purpose. So marriage is generally perceived as space which enters people who agree (really or outwards) with this aim, meaning and purpose. Than is "entering marriage" valuable in according with societal context. Variety of people's attitudes to marriage is obvious and creates wide range of opinion and value orientation. Despite it most people in society close marriage or focus their activities towards this goal and value of marriage with larger or smaller changes remains. These values are created in processes of permanent interactions (it is not about value of individual or other individual subject - if marriage has value 
only for individual subject, it couldn't arise and function as social institution).

5. Institutions exist on form of socially institutionalized normative systems of rules (e.g. as institutions of law, ethics, culture or religion, for more see Geffert, 2010b:204) and as real individual cases of relevant institution. Example can be marriage as legally stated institution and example of marriage with statement of persons (husband and wife) and objects (relations, property) what organization theory and social knowledge view as establishment of organization with existence of active subject (connection and continuity of individual and organization).

6. Institution is only institutionalized as system of rules - and as such it is part of law or other normative order - or it is entity of social reality consisting of persons in certain relations and objects which are in relation to the institution or its persons included in the institution. It means that institution exist as model which shows certain way of behaviour also in "latent" condition - even when nobody performs it - as set of rules and guidelines. Except this it can function as social reality - in the moment when specific subject decides to accept this behavioural model in specific situation. Then institution on idea level becomes institution on practical level when with entry of subject happen "materialising" of institution in the organization form (formal or informal). Here institution becomes entity of social reality, basis on which is developed organizational behaviour which includes specific subjects in specific situation, formulation of intents, purposes and goals and also tool basement of activities.

7. Metaphorically it can be said that institutions live "their own life". In this regard it is justified to see in them objective realities sui generis. It is present let's say certain "moment of laziness" what means that institutionalized forms - e.g. legal institutions - stay preserved despite their meaning and purpose is over. It is problem of huge persistence of social institutions which is connected primarily:

a) with character of institution as behavioural model which is in its nature abstract - function as idea (global idea) - idea can hardly (can't ) be cancelled (as for example organisation),

b) with way of "statement" of institution as result of institutionalization process. It is usually long-term process which includes wide social acceptance (institution doesn't arise on basis of agreement between two persons), then so widely socially approved model is hard to "cancel",

c) institutions have ability of transformation, or tendency to certain development (adaptation on current conditions) and so their operation can be often misleading. Institution of marriage exists for whole centuries - in various cultures but its character, function, meaning in social reality has changed. This doesn't mean that its functionality in society automatically increases (as behavioural model).

8. Institutions get in tight connection with basic idea which the institution serves and by which is characterized its existence and its development. This global idea - central idea can explain basic characteristic of institution, but we shouldn't presume that form this encapsulated characteristic can be stated development of institution. "Own life" of institution excludes fossilization of central idea. Global idea is for character of institution cardinal, determining. It has key function at activation of organized behaviour in case that a subject exists which will 
introduce global idea "in life" - in social unit in materialized form of social unit. 9. Institution is despite high degree of universality in many cases very strongly connected with environment in which it has emerged and stabilized. "Transfer" in the other environment assume necessary range of institution modification with regard to character of new environment. According to this, it is applicable that institution (e.g. know how) which was in its original ("parental") environment highly effective will be in new conditions little effective or fail or require such intensive interventions in its substance that it is more convenient to think of development of original models then using of "borrowed ones".

All institutions have certain common signs; otherwise they can be of different type so the term institution creates more generic than individual term. Institutions have common relation to context of action, i.e. their function is determination of individual and social behaviour, they are connecting segment between action of individuals and societies in which individuals belong and they are connected to core of socially existing practical information, primarily normative regulators.

\subsection{Purposes and goals}

Purposes have to be understood, by Weinberger, as volitional actions of subjects as expression of certain direction of activity (not spontaneous but intentional). Their use or function is not to label the object. They have certain situational content, describing state which shall be reached or express their relation to desired state (goal) or set measure of action. They are set of contents which with its meaning respect character of goals.

For example goal of non-profit organisation is to gain financial means for project for educational activities of unemployed. This is explicitly formulated goal which can be described in various ways when this description also contains (includes) determination of means for its reaching. Then purposes can be understood as set of contents and means, activated on the way to the goal (long-term, short-term).

Constitutive element of purpose is that certain content is determined as desired (intended). What does it mean can be explained only by showing its pragmatic function of purposes i.e.: that they present decisive function for determining of action with regard to stated goal.

Purpose content can be reaching of certain state, final state that shall be reached. As purpose can act also orientation value which shall be kept (compare also the term homeostasis) or it is stated desired stable state (e.g. prosperity as purpose) or goal which fulfilment is time-consuming process (e.g. to learn English).

For purpose it is not deciding if its content expresses end, final point of action which is considered for stated purpose but the fact that certain content is presented as desired, as through action satiable wanting. According to this term purpose and goal can't be used as synonyms. 
Goal is with its character in position of "reached" state: one-off - to get investor, for development in IT sector of one organizational department of autonomous government in specific region), or permanently - to provide effective services for citizens - clients.

Purpose is everything that can be included in the "content" of action and decisionmaking, i.e. set of tools (ideas, strategies, character of resource distribution - human, information etc., way of coordination and management, way of communication...).

For activation and dynamizing of purposes and goals important role plays what Tuomela (2003) calls "collective acceptance", that basically says the parts of the social world it applies to are collectively constructed and man-made" (2003:157).

\subsubsection{Relations between purposes and goals, dynamics of purposes and goals}

Content of purpose determination can be specific in different measure. So can between purposes relations of superiority and subordination as well as purpose assignments arise. Relations between purposes and goals don't exclude conflict between purposes and goals (e.g. if goal is reached with inadequate means or purpose system indicates direction of system to other than officially demonstrated goals; or possibilities within area of resources indicates unreality of reaching stated goal etc.).

System of purposes is system of real tendencies, not description of possible world; conflicts belong in certain sense to substance of these systems. These conflicts are not purpose system deficiencies which could make them unusable.

Purpose system has its dynamics (applicable also for goals). Already Wilhelm Wundt alerted on important psychological fact. His term purpose heterogony shows the fact that man at observing of so far accepted purposes and goals on basis of experience and probably also because of new life situations in world and on basis of new technical and social possibilities composes new purposes, enlarges and modifies his target statements.

There exists also change of purpose system assigned to certain person or other subject on grounds of individual's or society's development (or other societies). E.g. constellation of small business purposes will be significantly changed if it will expand to large business.

Usually at system analysing (e.g. institutions or organisation) we compose basic goals which are relatively stable and determine essential intentions. These goals however can be in various relations to other system goals - superior, inferior, assigned independent, dependent etc. This phenomenon is called optical relativity of goals because of all goals and their analyses or analyses of from them resulting facts or with them related facts are parts of sophisticated complex relations within system and between systems. For example goals of National employment bureau are clearly stated, they are reasons why these office were established and works. These goals 
are stated regardless on other circumstances. When composing these goals into goals of other structures, e.g. Ministry of Labour, Social Affairs and Family of the Slovak republic or individual goals of the unemployed person, goals of National employment bureau gain more precise but above all differentiated contours.

\section{From institution to formal organization}

Social institutions same as "their" organizations are based on norms and they can't be understood only as simple regularities of behaviour. But "institutions are to be distinguished from formal organizations and from social organization: an organization is a set of empirical institutions bounded by membership, foundation and dissolution and with at least one explicitly prescribed purpose which is supposed ideally to govern the collective action of these members (Perri, 2003:397)".

Normative systems (laws, moral...) determine behaviour which "shall be" or "may be" but this don't use up their social function. In according with norms are divided competences, is constituted right to power, organizations which creates space for possible action and mainly where behaviour or action of individual is connected with institutional framework (I can get married only if legal institution of marriage exists).

Process of institution forming towards creation of organized environment is closely connected to system of purposes and goals. Line between institution and organization is visible in moment of concretization of normative attributes (norms which determine character of institution differ from norms which provide operation of organization although their mutual connection is inevitable - therefore base for existence and function of institution and also base for existence and function of organizations is "normative system" - system of rules.

Institutionalization of societal life means permanent socialization of individual activities, intents, and ways of acting. It means that institution is exclusively social phenomenon which assumes certain "audience" and range of its acceptance in relation to stated rules.

Institution is not exactly specified on level of action subject. Action subject can be any person or group (team). Subject specification stadium assume development of strictly limited unit which with regard to institutional purposes and goals directs its action. Only subject can set goal of its function (this goal "excuses" existence and function of organization) and to create purpose system as tools for its reaching (achieving).

In relation to institution we can't talk about subject as its substance is connected with idea - "global idea" and its wide social approval (legitimization). It means that "it is here even when it is not performed". 
Establishment and function of organization is not possible without existence of subject (which realizes it).

\subsection{How to distinguish institution from organization}

Institution as pattern and model of behaviour is characterized by certain universality. Universality is its basic characteristic in relation to intercultural specifics. That means that substance of institution is everywhere understood equally (if the institution already exists) but its content and normative limitation can show mutual differences. For example in each culture which knows education system, that system means the same (education system, system of training and education, system educational-training, system of organizations which provide education, system eliminating illiteracy etc.)

Differences can occur already on level of normative regulators - somewhere is by law provided free access to education somewhere is considered self-financing also from school fees, somewhere it is obligatory, somewhere optional. Further there may exist differences within the institution (e.g. position of private schools in relation to state and religious schools).

Universality on level of organizations is controversial. It exists mainly on level of "global idea". Each real organization is with its character of function significantly connected with conditions in which it follows its goals (economic, legislative, social, political, cultural etc.), it can't be omitted that each organizational unit is necessary to understand as unique specific organizational area although through goal ideas of subject it is connected to "idea" which functions universally - each school is significantly specific, unique organizational unit despite all schools realize idea of education and training in relatively equal (social) conditions.

Global idea is determined by purpose or set of purposes due to which institution has been established and exists. It provides continuity of model - institution and its organization.

Continuity means that establishment of institution (on basis of global idea) and institutionalization process (creation of normative limitation of institution and its integration in the social environment) is parallel with development of organization background of institution. E.g. global idea of education could arise but it was realised only by establishment of the first school. So we can say that development of institution follows certain purpose (and prepares "ground" for system of purposes as tools - for reaching of goal determined by subject as reason for establishment of organization) and organization exists in view of certain goal (in this context is especially suitable to differ purposes and goals and don't use them as synonyms. Could this happen also reversely? Was it necessary to set global idea of education to first school being established? Is establishment of one school sufficient for developing of school institution? - Definitely not because except its normative determinations, social acceptance is for the institution characteristic also certain regularity and repeatability. 
It is hard to answer the question - what was first, institution or organization (although global idea is connected primary with institution, in organizational conditions finds its by goal limited possibilities for realization in praxis).

\section{Conclusion}

The Weinberger's normative institutionalism can be very useful in reaching the appropriate approach to many organizational attributes explanation. Generally, institutions are studied as dynamical patterns of the behaviour of individuals (or any social subject). The changes of institutions are in normative institutionalism viewed as a process of adaptation to broader social context (March and Olson, 1989). The process of learning is characterized here by the changes of codes of conduct in organizations - as punctuated equilibria. This framework, with its typical attributes, can create respectable basis for the study of organizations as complex learning systems (Bolfíková, Hrehová and Frenová, 2010), dynamic systems, complex adaptive systems (Stacey, 1996).

The sense of Weinberger's institutionalism use can be found especially in this area of organizational theory, that is connected with non-linearity in administrative systems behaviour (Kiel, 1994), the possibility to create the space of freedom by the production of alternatives and variations in decision-making processes (using the normative sentences with operator "can be"), the direction of causality (in action theory), that is defined also for chaotic deterministic systems.

The "life of institutions" is also inspirational - firstly their stability, that can represent one of the paradoxes of complex adaptive systems (Stacey, 1996) - continual production of new models of behaviour and the functioning of the old ones at the same time. This is the key moment of the remaining of bureaucratic systems explanation.

The logic of Weinberger's institutionalism can be helpful in the theoretical-empirical research of organizations in regard with the attributes of bureaucratic - typical governmental (Bolfíková, 2009) and post-bureaucratic - typical cooperative mechanisms (in creation, as well as the changes of the values and rules, in decision-making, communication, relationships, balance between routine and change, etc.). There are also other possibilities of the application of the institutionalism in the study of organizations. The specific areas can be discussed in future studies.

\section{References}

1. Austin, J. (1954). The Province of Jurisprudence Determined. H.L.A. Hart.

2. Baptista, J. (2009). Institutionalization as a process of interplay between technology and its organizational context of use. Journal of Information Technology, 24 (4).

3. Bolfíková, E. (2009). From Bureaucracy to Inteligent Administration. In: Naukova mysl informacyjnego wieku. Przemysl. Nauka i studia:43-51. 
4. Bolfíková, E., Hrehová, D. and Frenová, J. (2010). Manager's decision-making in organizations - empirical analysis of bureaucratic vs. learning approach. Zbornik Radova Ekonomskoj Fakulteta u Rijeci, 28 (1):135-163.

5. Broom, L. and Selznick, P. (1955). Sociology: A Text with Adapted Readings. New York: Row, Peterson.

6. Clark, P. (1985). A review of the theories of time and structure for organizational sociology, in: Bacharach, S.B. and Mithell, S.M. (Eds.). Research in the sociology of organizations. Greenwich, CT: JAI Press:35-79.

7. Coleman, J. L. (1991). Rules and Social Facts. Harvard Journal of Law E Public Policy, 14 (3):703-726.

8. Dewey, J. (1930). Human Nature and Conduct: An Introduction to Social Psychology. New York: The Modern Library of Random House.

9. DiMaggio, P. J. and Powell, W. W. (1983). The iron cage revisited: Institutional Isomorfism and collective rationality in institutional fields. American Sociological Review, 48 (1):147-160.

10. DiMaggio, P. J. and Powel, W. W. (1991). Introduction, in: Powel, W.W. and DiMaggio, P. J. (Eds.). The New Institutionalism in Organizational Analysis. Chicago: University of Chicago Press.

11. Dobiaš, D. (2009). The Idea of Rationalism of K. R. Popper as a Phenomenon of Spiritual History of Europe, in: Dobiaš, D., Gbúrová, M. and Mattová, I. (Eds.). Intercultural dialogue. Present state - Contexts - Perspectives. Prešov: 16 - 32.

12. Douglas, M. (1980). Evans-Pritchard: His Life, Work, Writings and Ideas. London, Brighton: Harvester Press in association with Fontana.

13. Douglas, M. (1986). How Institutions Think. London: Routledge \& Kegan Paul.

14. Geffert, R. (2008). Ethical Dimension of Public Administration. Tools of Ethics in Public Administration. Public Administration and Society, 9 (1/2):52-59.

15. Geffert, R. (2010a). Ethics in Public Administration. Košice: University of Pavol Jozef Šafárik.

16. Geffert, R. (2010b). Ethics, Morality and Law, in: Gluchman, V.(Eds.). Ethics of Public Administration. Prešov: University of Prešov:203-220.

17. Harvey, J. T. and Katovich, M. A. (1992). Symbolic Interactionism and Institutionalism: Common Roots. Journal of Economic Issues, 26 (3):791-812.

18. Jensen, H. E. (1987). The Theory of Human Nature. Journal of Economic Issues, 21 (6):1039-1073.

19. Jepperson, R. L. (1991). Institutions, institutional effects and institutionalism, in: Powell, W. W. and DiMagio, P. J. (Eds.). The New Institutionalism in Organizational Analysis. Chicago: University of Chicago Press:143-163.

20. Kiel, L. D. (1994). Managing Chaos and Complexity in Government. A New Paradigm for Managing Change, Innovation, and Organizational Renewal. San Francisco: Jossey-Bass Publishers.

21. Knight, J. (1992). Institutions and Social Conflict. Cambridge: Cambridge University Press.

22. Lawrence, T. B.; Winn, M. I. and Jennings, P. D. (2001). The Temporal Dynamics of Institutionalization. Academy of Management Review, 26 (2):7-28.

23. March, J. G. and Olsen, J. P. (1984). The New Institutionalism: Organizational factors in political life. American Political Science Review, 78:738-749

24. March, J. G. and Olson, J. P. (1989). Rediscovering Institutions. New York: The Free Press. 
25. North, D. C. (1990). Institutions, Institutional Change and Economic Performance. Cambridge: Cambridge University Press.

26. Perri 6 (2003). Institutional Viability: a Neo-Durkheimian Theory. Innovation, 16 (4):395-415.

27. Peters, B. G. (1999). Institutional Theory in Political Science: the „New Institutionalism". London: Pinter.

28. Powell, W. W. (1991). Expanding the scope of institutional analysis, in: Powell, W. W. and DiMaggio, P. J. (Eds.). The new institutionalism in organizational analysis. Chicago: University of Chicago Press:183-203.

29. Powell W. W., and DiMaggio, P. J. (1991). The new institutionalism in organizational analysis. Chicago: University of Chicago Press.

30. Raz, J. (1979). The Authority of Law: Essays on Law and Morality.

31. Rogers, E. M. (1995). Diffusion of innovation (4th ed.). New York: Free Press.

32. Schauer, F. (1991). Playing by the Rules.

33. Scott, W. R. (1991). Unpacking institutional arguments, in: Powell, W. W. and DiMaggio, P. J. (Eds.). The new institutionalism in organizational analysis. Chicago: University of Chicago Press:164-182.

34. Scott, W. R. (1995). Institutions and organizations. Thousand Oaks, CA: Sage.

35. Searle, J. R. (1995). The Construction of Social Reality. New York: The Free Press.

36. Searle, J. R. (1998). Mind, Language and Society: Philosophy in the Real World. New York: Basic Books.

37. Selznick, P. (1957). Leadership in Administration. New York: Harper and Row.

38. Selznick, P. (1992). The Moral Commonwelth: Social Theory and the Promise of Comunity. Berkeley: University of California Press.

39. Selznick, P. (1996). Institutionalism „Old“ and „New“. Administrative Science Quarterly, 41(2): 33-41.

40. Stacey, R. D. (1996). Complexity and Creativity in Organizations. San Francisco: Berett-Koehler Publishers

41. Strang, D. and Tuma, N. B. (1993). Spatial and temporal heterogenity in diffusion. American Journal of Sociology, 99 (4):614-639.

42. Tuomela, R. (1995). The Importance of US: A Philosophical Study of Basic Social Notions (Stanford Series in Philosophy). Stanford, Calif: Stanford University Press.

43. Tuomela, R. (2003). Collective Acceptance, Social Institutions, and Social Reality. American Journal of Economic and Sociology, 62 (1):123-165.

44. Tuomela, R. and Balzer, W. (1999). Collective Acceptance and Collective Sotial Notions. Synthese, 117:175-205.

45. Viskovatoff, A. (2003). Searle, Rationality, and Social Reality. American Journal of Economics and Sociology, 62 (1):7-44.

46. Zucker, L. G. (1983). Organizations as Institutions, in: Bacharach, S.B. (Ed.). Research in the Sociology of Organizations. Greenwich: JAI Press:1-47.

47. Weinberger, O. (1995). Inštitucionalizmus. Nová teória konania práva a demokracie. Bratislava: SOFA.

48. Williams, B. (1981). „Internal and External Reasons“ In idem., Moral Luck. Cambridge: Cambridge University Press. 
Izvorni znanstveni rad

\section{Eva Bolfiková}

University of P.J. Šafárik in Košice, Faculty of Arts, Department of Political Science, Slovak Republic e-mail: eva.bolfikova@upjs.sk

\section{Daniela Hrehová}

Technical University in Košice, Department of Social Sciences, Slovak Republic

e-mail: Daniela.Hrehova@tuke.sk

\section{Jana Frenová}

Faculty of Management, The University of Prešov, Slovak republic

e-mail: ecperson@interdum.sk

\section{Normativni institucionalizam, institucionalna baza organizacije}

\section{Sažetak}

Članak predstavlja Weinbergerov normativni institucionalizam i teoriju akcije kao osnovu rješenja nekih odabranih pitanja o odnosu između institucionalnog ponašanja i formalnih organizacija. Ukazuje na vitalnost kolaborativnih mehanizama u društvenim sistemima i nudi različita razmišljanja i sumnje u vezi sadržaja racionalnih modela formalnih organizacija i metodološkog individualizma (Weber).

Ključne riječi: institucija, institucionalizam, organizacija, teorija akcije, informacija. 